\title{
La vocación universitaria de la teología
}

\section{Theology's University Vocation}

\section{José Serafín BÉJAR}

Facultad de Teología de Granada

Granada. España

ID ORCID 0000-0002-3170-5367

serabejar@gmail.com
Resumen: La vocación universitaria de la teología consiste en hacer capaz a la razón, para que pueda encontrar logos universal en un acontecimiento particular: Jesús de Nazaret. Esta vocación podría entenderse hoy como un necesario discernimiento de las racionalidades que están en vigor en el seno de las universidades actuales. Por este motivo, el autor hace un recorrido por aquellas racionalidades que, siendo permeables a la fe, se encuentran vigentes de modo más significativo en el escenario de nuestro tiempo. En concreto, se analizan la «manifestación» en M. Heidegger, la «carne» en E. Levinas y la «donación» en J.-L. Marion.

Palabras clave: Teología, Universidad, Discernimiento de las racionalidades, Manifestación, Carne, Donación.
Abstract: Theology's university vocation consists in rendering reason capable of finding the universal logos in a particular event: Jesus of Nazareth. This vocation can be perceived as a necessary discernment of the rationalities that permeate the very core of today's universities. For this reason, the author provides an overview of the rationalities that, being open to faith, currently predominate in the world. Concretely, the author analyzes «manifestation» in M. Heidegger, «flesh» in E. Levinas, and «donation» in J.-L. Marion.

Keywords: Theology, University, Discernment of Rationalities, Manifestation, Flesh, Donation. 
$E$ n la presente reflexión, se nos pide poner en correlación dos realidades: Teología y Universidad. Este esfuerzo de correlación se realiza en momentos en los que han perdido evidencia las conexiones mutuas que, en relación a dichas realidades, antaño podían resultar obvias. Se nos demanda así volver a pensar aspectos esenciales de nuestra experiencia creyente, para poder ofrecer reformulaciones que respondan a los nuevos tiempos.

En concreto, vamos a tratar en esta exposición acerca de la vocación universitaria de la teología. Intentaremos fundamentar dicha vocación y ofrecer una hipótesis de trabajo que nos permita comprender el quehacer teológico en contexto netamente universitario. De esta manera, evidenciaremos los aportes mutuos que la teología y la universidad pueden prestarse para un mejor servicio al mundo.

\section{El PLANTEAMiENTO DE LA CUESTiÓN}

La pregunta fundamental a la que tiene que responder la teología cristiana, podría formularse de la siguiente manera: ¿por qué «este» hombre es «el» hombre donde «todo» hombre encuentra salvación? Así, desde el comienzo mismo de la irrupción del acontecimiento cristiano, el cristianismo tuvo que legitimarse como aquella religión que unía en sí la historia particular de un judío del siglo I y su significación universal para todos los hombres de todos los tiempos. Es precisamente aquí donde vemos reflejada, en su manera más honda, lo que podríamos llamar la vocación universitaria de la teología. En efecto, la teología tiene como vocación última «hacer capaz» a la razón, para que ésta pueda concebir sin «repulsión» que lo universal se encuentra en la concreción de este rostro humano: ¿por qué «este» hombre es «el» hombre donde «todo» hombre encuentra salvación?

Desde aquí podemos explicar el encuentro primigenio entre el cristianismo de los orígenes y el potente Logos griego. La nueva fe no se sintió nunca ligada a las religiones del momento que, en sus expresiones cultuales, servían como legitimación del orden político y social establecido. Su polo de atención siempre se dirigió al ámbito del pensamiento, donde se buscaba el «Logos» que unificara el conjunto de la realidad; es decir, el «Logos» con una pretensión de universalidad. A este propósito, refiere González de Cardedal:

La patrística no inició el diálogo con las religiones, sino que prefirió instaurar comunicación y colaboración con la filosofía, porque sólo ella planteaba la cuestión de la verdad como esencial para la vida y para 
la fe. Las religiones de aquel momento estaban al servicio de la magia y del mito, de la ciudad y del emperador. Por eso los Padres prefieren la razón filosófica a la praxis religiosa vigente, a los ritos mistéricos o a la teología política. Las religiones quedan así degradadas a un nivel inferior tanto en función de la racionalidad como de la fe. Son algo superado uno vez que la revelación cristiana y la razón crítica han decidido ejercerse mutuamente ${ }^{1}$.

Ante estas búsquedas, el cristianismo primitivo ofreció su aporte peculiar: Jesucristo es el Logos eterno del Padre ${ }^{2}$. Comenzaba así un largo proceso donde la nueva fe tendría que ir auto-proponiéndose en un nuevo contexto, asumiendo aquellas vehiculaciones conceptuales que le podían servir en su tarea evangelizadora, al tiempo que resistiendo a aquellas seducciones que pudieran terminar por anular lo específicamente cristiano. Dicho de otra manera, la concreta labor de la teología se cifró en encarar un discernimiento de la racionalidad vigente en aquel tiempo, para resaltar sus potencialidades, pero también sus límites, en referencia al específico evento cristiano. De hecho, la nueva propuesta del cristianismo, para sorpresa de unos, y escándalo de otros, hará una hermenéutica del logos griego desde las categorías de Sarx (cfr. Jn 1,14) y de Ágape (cfr. 1 Jn 4,8) .

Podemos ir percatándonos, a partir de lo dicho, de que la teología encontrará en la universidad un enclave connatural a su misión. El surgimiento

${ }^{1}$ GonZÁlez de Cardedal, O., La teología en España (1959-2009). Memoria y prospectiva, Madrid: Encuentro, 2010, 112. A esto también se refiere Rodríguez Duplá, en relación al núcleo del pensamiento de J. Ratzinger, cuando habla de la triple distinción que realiza Agustín entre «teología mítica», «teología civil» y «teología natural». La primera está ordenada a la tradición, la segunda subordinada a la divinización de Roma, y la tercera al servicio de la verdad. Esta última, realizada por los filósofos, es la digna interlocutora del cristianismo naciente. En este sentido, se podría recordar la sentencia de Tertuliano: «Cristo se denominó a sí mismo la verdad, no la costumbre». Para estas ideas, cfr. Rodríguez Duplá, L., Prólogo, en Ratzinger, J. y Habermas, J., Dialéctica de la secularización. Sobre la razón y la religión, Madrid: Encuentro, 2006, 5-21.

2 A propósito de la disputa sobre la helenización del cristianismo, podemos leer: «Hay que conceder fundamentalmente que el cristianismo no podía soslayar una polémica con la pretensión universal de la filosofía griega del Logos y de la esencia precisamente a causa de la pretensión cristiana escatológico-universal; aquí no se trata de renunciar a sí mismo, sino de reafirmarse el cristianismo», en KASPER, W., fesús el Cristo, Salamanca: Sígueme, 1999, 220.

3 Así explica Kasper esta hermenéutica cristológica del Logos: «La unidad y belleza del mundo se funda en el único Logos, que todo lo gobierna. Por doquier y en todo se encuentran fragmentos y huellas del Logos. Los apologistas del siglo II incorporaron ya esta teoría, interpretándola cristológicamente. Según ellos, el Logos se reveló corporalmente en su plenitud en Jesucristo, mientras que en las religiones y filosofías gentiles sólo se hallan semillas de la verdad», en ibid., 235. 
de la institución universitaria, en el apogeo mismo de la Edad Media, se caracterizó por su vocación universal. La «universitas» surgía como el areópago de la verdad; una verdad que debía ser propuesta a todos como amparo y custodia de la condición humana. Aparecía así clara la convicción de que la razón era capaz de conocer la verdad y que, justamente el cristianismo, estaba sostenido en aquella verdad que había de ser propuesta a todos como universalmente válida; es decir, la persona de Jesucristo.

El papa Ratzinger, en su discurso frustrado en La Sapienza de Roma, recordaba las cuatro facultades que conformaban las universidades medievales: medicina, derecho, filosofía y teología ${ }^{4}$. En la cúspide de ellas se encontraba la teología, pero no por una suerte de arbitrariedad, que se impusiera al todo de una manera extrinsecista, sino por una motivación esencial: la teología aparecía como aquella facultad que unificaba el conjunto de lo real en torno a la idea de un logos propiamente cristiano. Esto es algo que siempre ha estado presente en el pensamiento de J. Ratzinger. En uno de sus ensayos de eclesiología, podemos leer la siguiente reflexión expositiva:

La universidad nació porque la fe consideraba posible la búsqueda de la verdad e impulsaba a esta búsqueda de tal modo que posteriormente requirió la extensión de su ámbito a todos los campos del conocimiento humano, naciendo así las diversas facultades. Éstas, a pesar de la diversidad de sus propios objetos, estaban sustentadas por la orientación común de buscar la verdad, cuya posibilidad estaba garantizada, en último término, como lo reconocían todas las facultades, por la facultad de teología. Puesto que el conocimiento humano se basaba en una unidad última, los sabios y los que aspiraban a serlo podían unirse en una Universitas de docentes y discentes ${ }^{5}$.

Sin embargo, esta unidad de la christianitas se va a ver interrumpida con la aparición y el apogeo del espíritu moderno y su específico ejercicio de racionalidad $^{6}$. La clave fundamental de comprensión de esta ejercitación de la razón será el desmentido de la historia como escenario de mostración de la verdad. En efecto, después del descubrimiento de América y del nacimiento de la

${ }^{4}$ Para conocer el pensamiento de Benedicto XVI en relación a la universidad, cfr. CANTOS APARICIO, M., Razón abierta. La idea de universidad en F. Ratzinger/Benedicto XVI, Madrid: BAC, 2015.

${ }^{5}$ Ratzinger, J., Iglesia, ecumenismo y política. Nuevos ensayos de eclesiología, Madrid: BAC, 1987, 172.

${ }^{6}$ Para las ideas que siguen, cfr. BÉJAR, J. S., «Cristianismo, Islam e Ilustración. A propósito del discurso de Benedicto XVI en la Universidad de Ratisbona», Pensamiento 64 (2008) 1025-1042. 
Reforma, con las consabidas guerras de religión, se busca verdad en el ámbito de lo natural. La historia nos separa con sus específicas tradiciones religiosas, y la modernidad se siente legitimada para indagar un nuevo suelo. Aflora así la querencia por una razón natural, por una moral natural, por una sociedad natural y por una religión natural.

Esto aparece claramente conceptualizado por G. E. Lessing, en su obra Sobre la demostración en Espiritu y fuerza (1777), y su diferenciación entre «verdades de hecho» $\mathrm{y}$ «verdades de razón». Las verdades de hecho están apegadas a la historia, son concretas y, por tanto, no pueden engendrar evidencia, ni pretender ser universalizables. Sin embargo, las verdades de razón son universales y abstractas, pudiendo ser propuestas a todos, de modo necesario, con el solo recurso a la luz de la razón natural. Así se explica el propio Lessing:

[...] no seré yo quien niegue que las noticias de aquellos milagros y profecías son tan atendibles como puedan serlo en todo caso las verdades históricas. Pero si sólo pueden ser tan atendibles, ¿por qué al mismo tiempo se las hace de hecho infinitamente más atendibles?

¿Cómo? Pues levantando sobre ellas muy distintas cosas y muchas más de las que se está autorizado a asentar sobre verdades históricamente probadas.

Si no puede demostrarse ninguna verdad histórica, tampoco podrá demostrase nada por medio de verdades históricas.

Es decir: Las verdades históricas, como contingentes que son, no pueden servir de prueba de las verdades de razón como necesarias que son ${ }^{7}$.

Las apreciaciones de Lessing se planteaban como un ataque frontal al elemento definitorio de lo cristiano; es decir, la encarnación. La pretensión de que el judío Jesús de Nazaret pudiera ser el criterio de verdad para todos los seres humanos que han sido, son y serán, acontecía, para este filósofo alemán, como un foso tan grande que no era posible saltar sobre él. No en vano, y a partir de esta específica ejercitación racional, el cristianismo de la ilustración será legitimado sólo y en la medida en que pueda engendrar un caudal de verdades morales que puedan ser ofrecidas al ser humano desde su potencial de razón. Así, el Jesús de los ilustrados será un maestro de moral, cuya personal pretensión está al margen de cualquier intencionalidad escatológica, de índole universal.

7 Lessing, G. E., «Sobre la demostración en espíritu y fuerza», en ANDREu Rodrigo, A. (ed.), Escritos filosóficos y teológicos, Madrid: Editora Nacional, 1982, 447. El subrayado es del propio texto. 
No obstante, en el escenario del romanticismo, se plantea un uso de la razón que es claramente diferenciable del ilustrado. Hegel recupera la historia, haciendo reaparecer la pretensión de absolutez del cristianismo, pero no acaba de superar el específico escándalo de lo cristiano. En efecto, sabe que la clave de perduración del cristianismo se encuentra en la posibilidad de que el absoluto se pueda mediar en la historia; y a ello consagra sus esfuerzos, sacando a la razón del ámbito de lo natural, y devolviéndola al ámbito de la historia. Sin embargo, dicha mediación del absoluto en el devenir histórico no puede quedar atada a un punto particular del mismo, ya que se hace necesaria la apelación a todos y a cada uno de los momentos que componen el proceso. Una de las afirmaciones fundamentales de su filosofía reza así: «La verdad es el todo» ${ }^{8}$.

Es interesante subrayar, en este sentido, que la teología liberal, en gran parte heredera de la influencia de este pensamiento, no supo salir de la fascinación de la filosofía del absoluto. No en vano, su propuesta teológica, que vemos muy claramente expresada en La esencia del cristianismo (1901) de A. Harnack, nos propone un cristianismo sin cristología. En efecto, late de fondo la convicción de que el Padre une a todos los hombres, mientras que el Hijo los separa. Así, el evangelio es únicamente evangelio del Padre, y el Hijo queda convertido en un mero profeta de un mensaje diáfano y claro: Dios y el alma; el alma y Dios. Así describe Ratzinger el pensamiento de Harnack, recogido en la obra que acabamos de citar:

La confesión de fe en el Hijo ha separado a los cristianos, no-cristianos y cristianos de distintas tendencias, pero lo que sabemos del Padre puede unirnos. El Hijo pertenece a muy pocos, pero el Padre pertenece a todos y todos a él; la fe ha separado, pero el amor puede unir. Lo que la fe ha dividido, puede unirlo el amor. Cristo predicó a todos los hombres que tenían un Padre común y así los convirtió en hermanos. Lo que ha provocado la ruptura decisiva, según Harnack, es que hemos convertido a Cristo en el Cristo predicado que exige la fe y que lo hayamos transformado en dogma. Jesús predicó un mensaje sin doctrina que proclama el amor ${ }^{9}$.

\footnotetext{
${ }^{8}$ Hegel, G. W. F., Fenomenología del Espíritu, Madrid: FCE, 2000, 16. Es interesante contrastar esta afirmación de Hegel con la también muy conocida de Adorno: «El todo es lo no verdadero», en AdORNo, Th. W., «Minima moralia. Reflexiones desde la vida dañada», en TiedemanN, R. (ed.), Obra completa, IV, Madrid: Akal, 2004, 55 (parágrafo 29).

9 RATZINGER, J., Introducción al cristianismo. Lecciones sobre el credo apostólico, Salamanca: Sígueme, 2005, 170. Para esta misma idea, cfr. GonZÁlez de Cardedal, O., Fundamentos de cristología, I, Madrid: BAC, 2005, 98 ss.
} 
Este breve recorrido por la historia del cristianismo tiene como objetivo mostrar lo que podríamos considerar nuestra hipótesis de trabajo. En efecto, si la vocación universitaria de la teología consiste en hacer capaz a la razón, para que pueda encontrar logos universal en un acontecimiento particular; a nuestro juicio, esta vocación podría entenderse hoy como un necesario discernimiento de las racionalidades que están en vigor en el seno de las universidades actuales. La pretensión de verdad de nuestra fe sólo puede ser ofertada si somos capaces de encontrar modulaciones de la razón que la hagan posible. Por este motivo, y como un modo de ejemplificar lo que estamos diciendo, podría ser interesante que hiciéramos un recorrido por aquellas racionalidades que, siendo permeables a la fe, se encuentran vigentes de modo más significativo en el escenario de nuestro tiempo ${ }^{10}$.

\section{LA TEOLOGÍA Y EL DISCERNIMIENTO DE LAS RACIONALIDADES}

En su discurso en Ratisbona del año 2006, el papa Benedicto hablaba de la misión de la teología como del esfuerzo por poner en correlación la fe con la razón común ${ }^{11}$. Nos parece que es una buena definición para remarcar la dimensión hermenéutica del quehacer teológico. En efecto, el teólogo, partiendo del dato revelado, tiene que ir a las racionalidades vigentes en su tiempo para poner de manifiesto connivencias que le permitan mostrar con credibilidad la oferta de salvación que aporta el cristianismo. Al mismo tiempo, este viaje de ida al ámbito de la razón le posibilita un retorno al ámbito de la revelación, donde ésta pueda ser entendida en mayor profundidad y actualizada a la altura de cada tiempo nuevo. Esta circularidad hermenéutica, que toma siempre el dato revelado como primero y normativo, estaba ya presente en la reflexión de los padres, y la exponía magistralmen-

${ }^{10}$ Para la cuestión del discernimiento de las racionalidades, se puede acudir a nuestra tesis doctoral en filosofía, con el título El discernimiento de las racionalidades en F. F. Hinkelammert, Granada: UGR, 2016, que se puede encontrar en https://hera.ugr.es/tesisugr/25887117.pdf. También cfr. BÉJAR, J. S., «La evangelización de la universidad como discernimiento de las racionalidades», Cristianismo, universidad y cultura 6 (2013) 57-71.

${ }^{11}$ Concretamente, las palabras a las que nos referimos son: «Además, la universidad se sentía orgullosa de sus dos facultades teológicas. Estaba claro que también ellas, interrogándose sobre la racionabilidad de la fe, realizan un trabajo que forma parte necesariamente del conjunto de la Universitas scientiarum, aunque no todos podían compartir la fe, a cuya correlación con la razón común se dedican los teólogos», en https://w2.vatican.va/content/benedict-xvi/es/speeches/ 2006/september/documents/hf_ben-xvi_spe_20060912_university-regensburg.html. 
te S. Agustín con su adagio clásico: «cree para comprender y comprende para creer» ${ }^{12}$.

Pues bien, a continuación vamos a realizar un recorrido por aquellas racionalidades vigentes en el pensamiento actual y que, a nuestro juicio, pueden ayudar a crear una atmósfera propicia para que la esencia del cristianismo pueda ser propuesta sin resistencia de parte de la razón. Concretamente, queremos fijarnos en tres figuras significativas de la filosofía, que creemos que aparecen hoy como indiscutidas en cuanto a la influencia de sus planteamientos en el mundo universitario. Estas tres figuras son Heidegger, Levinas, y Marion, cuyos planteamientos nos permiten reivindicar nociones tales como «manifestación», «carne»y «donación» ${ }^{13}$. En diálogo con ellas, mostraremos el potencial de razón de la propuesta cristiana y ofreceremos algunas notas críticas sobre las racionalidades hegemónicas que están operativas en la universidad actual.

\subsection{Heidegger y la manifestación}

El comienzo del siglo XX, en lo relativo a la historia del pensamiento, tiene elementos revisionistas que pueden ser altamente sugerentes para el quehacer teológico. Concretamente, el pensador alemán M. Heidegger realiza un giro filosófico que tiene como objetivo escapar de un cierto angostamiento de los horizontes filosóficos de la modernidad. En efecto, la filosofía de la conciencia, llevada a cabo por el giro cartesiano y sus ulteriores desarrollos en Kant y en Hegel, había conocido un enquistamiento en la problemática sujetoobjeto. Heidegger piensa que el conocimiento de la realidad necesita de un nuevo comienzo que sea capaz de atender a lo no atendido.

Así es, lo no atendido nos remite, especialmente en la filosofía del segundo Heidegger, al espacio manifestativo. En el trasfondo de este pensamiento se

12 Sermo 43, 7, 9. Este adagio es altamente rentable para los planteamientos propios de una fenomenología hermenéutica. En este sentido, es interesante cfr. Ricoeur, P., Finitud y culpabilidad, Madrid: Trotta, 2011, 484 ss. Del mismo modo, esta interpretación hermenéutica aparece, en muchos autores, como determinante de la comprensión actual de la teología. Como ejemplo, podemos atender a las siguientes palabras: «The attempt to establish mutually critical correlations between an interpretation of a particular religious tradition and an interpretation of the contemporary situation», en TRACY, D., «Theology: Comparative Theology», en JonES, L. (ed.), Encyclopedia of Religion, Detroit: Macmillan Reference, 2005, 9131. También este autor refiere cómo «the theologian's task must be primarily hermeneutical», en IDEM, The Analogical Imagination: Christian Theology and the Culture of Pluralism, New York: Crossroad, 1991, 67.

13 Cfr. BÉJAR, J. S., «Para una teología de la misericordia», Proyección LXIII (2016) 145-158. 
encuentra su particular lectura de la historia del pensamiento occidental como la historia del olvido del ser. Un punto culminante en este relato de olvido lo ocupa la consabida crítica a la onto-teología, entendida como una falta de atención a la verdad sobre Dios, que ha quedado reducido a un ente, aun cuando pueda llamarse el ente primero y principal. De esta historia de olvido también participan los sucesivos desarrollos de la modernidad ilustrada, que centrando la problemática del pensar en el dualismo sujeto-objeto, han reducido la cuestión a una mera relación entre entes, que acaba desfondando la realidad. Esta historia del olvido del ser es comparada por el pensador alemán con un destierro:

El desterramiento así pensado reside en el abandono del ser de lo ente. Es la señal del olvido del ser, a consecuencia del cual queda impensada la verdad del ser. El olvido del ser se anuncia indirectamente en el hecho de que lo único que el hombre considera y vuelve siempre a tratar es lo ente. Como al hacer esto el hombre no puede evitar tener una representación del ser, también el ser se explica solamente como «lo más general» de lo ente, y que por ende lo abarca por completo, o como una creación del ente infinito o como lo hecho por un sujeto finito. Simultáneamente, y desde tiempo remotos, el «ser» aparece en lugar de «lo ente», y viceversa, los dos se mezclan y envuelven en una extraña confusión todavía impensada ${ }^{14}$.

Desde estas claves, podemos entender el giro (Die Kehre) que da lugar al segundo Heidegger y que tiene como intención última salir de esta historia de decadencia nihilista para buscar la posibilidad de un nuevo inicio. Esta segunda etapa del pensamiento del alemán tiene como objetivo la sustitución, en el ámbito filosófico, de la «pregunta» por la «escucha» y su fundamento último se halla en la necesidad de constatar lo que él denomina como la diferencia ontológica entre el ser y el ente. Afirma el propio Heidegger:

El pensar, dicho sin más, es el pensar del ser. El genitivo dice dos cosas. El pensar es del ser, en la medida en que, como acontecimiento propio del ser, pertenece al ser. El pensar es al mismo tiempo pensar del ser, en la medida en que, al pertenecer al ser, está a la escucha del ser. Como aquello que pertenece al ser, estando a su escucha, el pensar es aquello que es según su procedencia esencial ${ }^{15}$.

\footnotetext{
14 Heidegger, M., Carta sobre el humanismo, Madrid: Alianza, 2001, 52.

15 Ibid., 15 ss.
} 
El acercamiento al mundo de los entes está necesitado de una nueva atención a aquella realidad que los hace posibles, gracias a su aparición despresente ${ }^{16}$. Es aquí donde Heidegger empieza a barruntar la necesidad de manosear el lenguaje para que sea posible la creación de una nueva conceptualización que no quede reducida al mundo de lo ente y sea capaz de nombrar, aún en su naturaleza innombrable, este nuevo comienzo. De este modo, él plantea una cierta cesura que, sin desconocer las grandes aportaciones de las dos líneas fundamentales de pensamiento de la historia de la humanidad, icónicamente representadas en los términos de Logos y de Tao, sea capaz de avanzar este nuevo inicio. Es así como Heidegger ofrece a la consideración del pensar un nuevo concepto: Ereignis. O de otra manera, el nuevo nombre para el ser será justamente el de Ereignis, que no conviene traducir, para no cosificar su significado omniabarcante, dejando así en alto su representación como acontecimiento propiciante. Con sus propias palabras:

La palabra Ereignis ha sido tomada de la lengua actual. Er-eignen significa originariamente: asir con los ojos, esto es, divisar, llamar con la mirada, a-propiar. La palabra Ereignis, pensada a partir del asunto indicado, debe hablar ahora como palabra conductora al servicio del pensar. Pensada como palabra conductora, se deja traducir tan poco como la palabra conductora griega, Logos, o la china, Tao ${ }^{17}$.

Una de las caracterizaciones fundamentales de la Ereignis sería su naturaleza sobreabundante. Precisamente por este exceso, el acontecimiento propiciante es capaz de donar un espacio manifestativo, que es al mismo tiempo una retracción de sí, y que hace posible que los entes sean. Es lo que Heidegger denomina como «el claro del ocultarse del ser». Este acontecimiento no acontece sin más, sino que propicia la vida de los entes. O de otra manera, si los entes «son», el ser «se da» en su manifestación. Afirma el filósofo alemán:

En Ser y tiempo se dice precavidamente y con toda la intención: il y a l'Etre, esto es, «se da» el ser. El francés il y a traduce de modo impreciso el alemán «es gibt», «se da». Porque el «es» impersonal alemán que «se da» aquí es el propio ser. El «da» nombra sin embargo la esencia del

\footnotetext{
${ }^{16}$ Para lo que viene a continuación, sigo muy de cerca la magnífica tesis de MarTín MoriLlas, A. M., La nada en el segundo Heidegger y el vacío de oriente. Hermenéutica contrastativa, Granada: Editorial de la Universidad de Granada, 2003, 189-217. El texto íntegro de la tesis en https://hera. ugr.es/tesisugr/16760268.pdf.

17 Heidegger, M., Identidad y diferencia (edición bilingüe), Barcelona: Anthropos, 1988, 85-87.
} 
ser que da, y de ese modo otorga, su verdad. El darse en lo abierto, con lo abierto mismo, es el propio ser.

$\mathrm{Al}$ mismo tiempo el «se da» también se usa con la intención de evitar provisionalmente el giro idiomático «el ser es». Porque, efectivamente, por lo general se dice ese «es» de algo que es. $\mathrm{Y}$ a eso es a lo que llamamos lo ente. Pero resulta que precisamente el ser no «es» lo «ente». Si nos limitamos a decir del ser este «es», sin una interpretación más precisa, será muy fácil que nos representemos el ser como un «ente» del tipo de lo ente conocido, el cual, en cuanto causa, produce efectos y, en cuanto efecto, es causado ${ }^{18}$.

No es éste el lugar para hacer un análisis a fondo de esta cuestión. Sin embargo, la evocación de la misma en el contexto que nos ocupa tiene una intencionalidad profundamente teológica. En efecto, después de un tiempo de preeminencia de racionalidades que excluían por principio el término «revelación», entendido como un concepto dogmático y atávico, el segundo Heidegger permite la entrada, al corazón mismo del pensamiento, de términos tales como «aparición», «manifestación», «desvelamiento», «epifanía». Gracias a esta puerta de entrada, estos conceptos pueden ser ahora reivindicados con la carga de racionalidad que le es inherente.

De hecho, huyendo de todo posible hechizo de onto-teología, Heidegger pone de relieve el aspecto paradójico del acontecimiento propiciante, cuando lo describe desde la doble cara que le es connatural. En efecto, se trata de una manifestación ocultante, de una donación que únicamente es posible en la retracción de sí, o de un decirse callando... que conecta a la filosofía de comienzos del siglo XX con apreciaciones que bien podrían ser referidas a distintas tradiciones místicas o espirituales.

Esto que estamos diciendo no es ajeno a una teología de la revelación propiamente cristiana. Pero tampoco es ajeno a la atmósfera que se respira en la inmensa mayoría de universidades. El propio Heidegger nos pone en alerta al decirnos que la expresión más palmaria de este olvido del ser, que deja todo reducido a puro ente, y que genera una tendencia al nihilismo, es el triunfo de la racionalidad tecnológica. Escuchemos sus propias palabras, donde reclama una liberación técnica del pensar, que arrastramos en Occidente desde Platón y Aristóteles:

${ }^{18}$ Heidegger, M., Carta..., cit., 44 ss. 


\section{JOSÉ SERAFÍN BÉJAR}

Desde entonces, la «filosofía» se encuentra en la permanente necesidad de justificar su existencia frente a las «ciencias». Y cree que la mejor manera de lograrlo es elevarse a sí misma al rango de ciencia. Pero este esfuerzo equivale al abandono de la esencia del pensar. La filosofía se siente atenazada por el temor a perder su prestigio y valor si no es una ciencia. En efecto, esto se considera una deficiencia y supone el carácter no científico del asunto. En la interpretación técnica del pensar se abandona el ser como elemento del pensar ${ }^{19}$.

Esta reducción del horizonte del pensar también será denunciado, desde otros presupuestos filosóficos, por la Escuela de Frankfurt, con el conocido nombre de «la crítica a la razón instrumental» ${ }^{20}$. Desde estas breves acotaciones, un detenido discernimiento de las racionalidades, por parte de una teología con vocación universitaria, está, a nuestro juicio, claramente justificada. De hecho, y a la luz del texto anteriormente aducido, la reflexión de Heidegger podría aplicarse de modo evidente no sólo a la filosofía, sino a la propia teología. En efecto, la situación tanto de la filosofía, como de la teología, en el actual escenario de la universidad, se encuentra claramente igualada, a la manera de un cierto destino trágico, que es urgente revertir.

\subsection{E. Levinas y la carne}

¿Qué es lo que aparece cuando el «ser» se da? Levinas nos dirá, en diálogo con Heidegger, al que tiene como interlocutor, pero desde un acercamiento decididamente crítico, que es la «carne» aquello que hace su aparición. La apelación de Heidegger al ser, y su captación de lo ente precisamente por aquello que no debe identificarse con el ser, tiene para Levinas el sabor de una totalización que corre el peligro de perpetuar una historia de la filosofía occidental que ha privilegiado el «todo» por encima de lo «singular». En otras palabras, a Levinas no le resulta grato el carácter anónimo, indeterminado y un tanto neutral del ser. Por esta razón, Levinas propone una atención al ente

9 Ibid., 13 ss.

20 Para la cuestión de la reducción de la teoría del conocimiento a teoría normativa de la ciencia, urgiendo la necesidad de ampliar la problemática desde una crítica que se entienda como teoría de la sociedad, cfr. Adorno, Th. W., Popper, K. R., Dahrendorf, R., Habermas, J., Albert, H. у Pilot, H., La disputa del positivismo en la sociología alemana, Barcelona-México D.F.: Grijalbo, 1973; y Habermas, J., Conocimiento e interés, Madrid: Taurus, 1988. 
concreto que, sin embargo, no sea interpretado como una nueva versión del anteriormente referido «olvido del ser» ${ }^{21}$.

En efecto, la totalidad consiste en la interposición de un término intermedio entre el otro y el yo, que reduce dicha otreidad a pura mismidad ${ }^{22}$. Este término intermedio puede venir dado por la prioridad del concepto, en clara referencia a Hegel, o también por una comprensión del ente a través de la mediación asfixiante del ser, si se hace alusión a Heidegger.

Sin embargo, Levinas reivindica la transcendencia de la relación con el otro, que se expresa a través de la idea cartesiana del infinito en mí. Con esta idea de infinito, se hace alusión a aquel deseo nunca realizable, o aquel concepto nunca tematizable, que pone de relieve la no homogeneización del otro a mí mismo. En otras palabras, Levinas quiere subrayar la absoluta exterioridad del otro con respecto al sujeto que lo piensa. Esta exterioridad inaferrable hace su aparición en el rostro de cada ser humano. Afirma el filósofo judío:

La idea de lo Infinito, infinitamente más contenida en lo menos, se produce concretamente con la modalidad de una relación con el rostro. Y sólo la idea de lo infinito mantiene la exterioridad del Otro con referencia al Mismo, a pesar de esta relación. De suerte que aquí se produce una articulación análoga al argumento ontológico: en la especie, la exterioridad de un ser se inscribe en su esencia. Sólo así no se articula un razonamiento, sino la epifanía como rostro. El deseo metafísico de lo absolutamente Otro que anima el intelectualismo (o el empirismo radical que confía la enseñanza a la exterioridad) despliega su en-ergía en la visión del rostro o en la idea de lo infinito. La idea de lo infinito sobrepasa mis poderes (no cuantitativamente, sino, como veremos más adelante,

${ }^{21}$ Esta incomodidad de Levinas con la visión heideggeriana del ser se pone de manifiesto, con un toque de ironía, en un comentario del filósofo judío, en una entrevista realizada en París en 1979, donde afirma: «Heidegger intenta separar el ser de Dios. Mi posición es separar a Dios del ser». Para esta cita, cfr. SUDAR, P., «¿La filosofía amor a la sabiduría o sabiduría del amor? Diálogo con Emmanuel Levinas», Teología 33 (1979) 64. Del mismo modo, en LEVINAS, E., Totalidad e infinito. Ensayo sobre la exterioridad, Salamanca: Sígueme, 2002, 211, se afirma: «No lucho con un dios sin rostro, sino que respondo a su expresión, a su revelación».

22 «En la filosofía se descubre una constante que permanece como esencial: es la interiorización de lo real para que nada pueda ser exterior a mi yo. Primacía absoluta del yo. Toda la filosofía es filosofía de la libertad; de allí que es concebida como autonomía [...] En mi filosofía no es la libertad la primera noción. Es la heteronomía y no el saber. Es la responsabilidad implicando en ello la sujeción a otro», en SUDAR, P., «¿La filosofía...», cit., 64. 
al cuestionarlo). No viene de nuestro fondo a priori y, por ello es la experiencia por excelencia ${ }^{23}$.

Así pues, si la atención a lo no atendido había llevado a Heidegger a un centramiento en la prioridad del ser, en Levinas la detención en aquello no suficientemente atendido nos conduce al descubrimiento de la carne. Se trata de una novedad de la filosofía del pasado siglo XX que no es exclusiva del pensador lituano, ya que esta atención a la carne puede ser también encontrada en las filosofías de Merleau Ponty ${ }^{24} \mathrm{y}$ de Michel Henry ${ }^{25}$, por poner algunos ejemplos. No obstante, la apelación a lo carnal tiene en Levinas una peculiaridad fácilmente reconocible, a la que ya hemos hecho referencia: la centralidad del rostro. De hecho, en su obra Totalidad e infinito, se nos ofrece una sugerente definición de esta significativa parte de nuestra corporeidad: «El modo por el cual se presenta el Otro, que supera la idea de lo Otro en mí, lo llamamos, en efecto, rostro». Merece la pena que sigamos leyendo la explanación de Levinas:

Este modo no consiste en figurar como tema ante mi mirada, en exponerse como un conjunto de cualidades formando una imagen. El rostro del Otro destruye en todo momento y desborda la imagen plástica que él me deja, la idea a mi medida y a la medida de su ideatum: la idea adecuada. No se manifiesta por estas cualidades, sino katba autó. Se expresa. El rostro, contra la ontología contemporánea, aporta una noción de verdad que no es el desvelamiento de un Neutro impersonal, sino una expresión: el ente perfora todas las envolturas y generalidades del ser, para exponer su «forma», la totalidad de su «contenido» $[\ldots]^{26}$.

Como se podrá percibir, el rostro es la parte de nuestro cuerpo que rompe con el imperio del yo. Para Levinas, el rostro tiene un valor epifánico, porque acontece como una metáfora de aquello que es absolutamente singular en nosotros. No ha habido dos rostros iguales que hayan brillado al amparo del sol de este mundo. Así, el rostro se niega a todo intento de posesión porque, más allá de la forma pura que lo delimita, irrumpe en su aparición a nosotros un elemento de incondicionalidad e infinitud. No hay analogía posible con el propio yo, ya que instaurar dicha analogía, por muy desproporcionada que

${ }^{23}$ LeVInAS, E., Totalidad..., cit., 209.

${ }^{24}$ Cfr. Merleau-Ponty, M., Fenomenología de la percepción, Barcelona: Planeta-Agostini, 1985.

${ }^{25}$ Cfr. Henry, M., Encarnación, Salamanca: Sígueme, 2001.

${ }^{26}$ Levinas, E., Totalidad..., cit., 74 ss. 
fuera, supondría un acercamiento a la homogeneización con el sí mismo que no nos está permitida. Frente a toda tentación de identidad, la exterioridad del rostro es la manifestación de una diferencia absoluta ${ }^{27}$.

Es así como se hace patente la lógica de lo singular, a partir de la aparición de la carne. En el plano concreto de la existencia no hay posibilidad de afirmar ninguna forma de sistema, ya que lo único que podemos encontrar es la apelación a lo concreto. Se trata del paso de la captación sofocante del otro como un sí mismo, a una nueva manera de relación con el mundo que está presidida por cierta pasividad contemplativa. Para Levinas, la contemplación del rostro de cada ser humano es siempre prohibición e invitación. Por una parte, la prohibición consiste en la afirmación de un límite infranqueable que, en clave normativa, podría traducirse como un «no matarás»:

Este infinito, más fuerte que el homicidio, ya nos resiste en su rostro, y su rostro, es la expresión original, es la primera palabra; «no matarás». Lo infinito paraliza el poder con su resistencia infinita al homicidio, que, duro es insuperable, brilla en el rostro del otro, en la desnudez total de sus ojos, sin defensa, en la desnudez de la apertura absoluta de lo Trascendente ${ }^{28}$.

Por otra parte, la invitación quiere hacer extensiva a cada ser humano una apelación a la responsabilidad. En efecto, la apertura a la epifanía de la irrupción de la eternidad en el tiempo, de lo absoluto en lo contingente, de la infinitud acontecida en el escenario de la historia, todo ello gracias al rostro, es una llamada a responsabilizarse del otro por amor ${ }^{29}$. Ahora lo finito e infinito no se entienden como meros contrapuestos, ya que lo infinito se comprende como una cualidad de lo concreto y singular. Subrayando esta dimensión de invitación, entendida como llamada, refiere Levinas:

El Otro permanece infinitamente trascendente, infinitamente extranjero, pero su rostro, en el que se produce su epifanía y que me llama, rompe con el mundo que puede sernos común y cuyas virtualidades se inscriben en nuestra naturaleza y que desarrollamos también por nuestra existencia ${ }^{30}$.

27 Cfr. Levinas, E., De otro modo que ser o más allá de la esencia, Salamanca: Sígueme, 2003, 152-156.

${ }^{28}$ LeVInAs, E., Totalidad..., cit., 212.

${ }^{29}$ Cfr. Levinas, E., De otro modo..., cit., 52 ss.

${ }^{30}$ Levinas, E., Totalidad..., cit., 208. 
En contraste con la neutralidad del ser, el rostro del otro aparece como filosofía primera. Levinas pretende una recuperación de la metafísica que va a venir de la reivindicación de la primacía de la ética con respecto a la ontología. Esto que decimos es fácil de comprender a partir de la categoría de resistencia. El rostro, en su verdad desnuda, muestra su resistencia a nuestra pretensión de poder, que busca siempre la reducción de la alteridad a una realidad en función de los propios deseos. La potencia de verdad, que brilla en cada rostro, es una llamada que no sólo es limitante, sino también creadora de libertad, ya que promueve nuestro deseo de bien y de bondad, de cuidado de los otros. Esta evocación de una responsabilidad hacia el otro por amor permite a Levinas reescribir el significado profundo de la filosofía, no como el amor a la sabiduría, sino más atinadamente como la sabiduría del amor. Afirma Levinas:

El rostro abre el discurso original, cuya primera palabra es una obligación que ninguna «interioridad» permite evitar [...] Al desvelamiento del ser en general, como base del conocimiento, como sentido del ser, le antecede la relación con el ente que se expresa; el plano ético precede al plano de la ontología ${ }^{31}$.

Como se podrá ver, en esta breve presentación que hemos realizado del filósofo judío, la teología puede encontrar connivencias muy significativas, que posibilitan un decidido discernimiento de las racionalidades hegemónicas en el mundo universitario. Concretamente, la crítica a la totalidad, que acaba reduciendo toda alteridad al imperio del propio yo, sería muy pertinente en nuestros días. El término intermedio que provoca esta reducción podría quedar referido a las distintas ideologías que, en sus versiones burguesas o revolucionarias, acaban convirtiéndose en las ideas normativas que rigen el funcionamiento de muchas universidades. Este específico discernimiento nos puede ayudar a no perder de vista la vocación social de la universidad y la necesaria búsqueda del bien común, más allá de los intereses de partido.

$\mathrm{Al}$ mismo tiempo, el pensamiento de Levinas ofrece horizontes diferenciables con aquellos que aportaba la modernidad ilustrada, a la hora de entender el potencial de verdad del cristianismo, tal como hemos comentado anteriormente a propósito de Lessing. Puede ser muy sugerente considerar una nueva comprensión de la verdad que está ligada a la singularidad de cada ser

31 Ibid., 214. 
humano, icónicamente expresada en la irrepetibilidad del rostro. No es difícil establecer, a partir de lo dicho, una conexión con la centralidad de la encarnación en el propio cristianismo. La verdad propuesta por la fe cristiana no se halla en una idea universal y abstracta, sino en una realidad personal y concreta. Así, podríamos decir que a mayor concreción, mayor alcance universal, ya que la verdad no está en el todo, sino en lo singular. El potencial de razón de este judío del siglo I puede significarse, desde este ejercicio de racionalidad, con unos horizontes amplios nada desdeñables.

\subsection{7.-L. Marion y la donación}

La atención a lo no atendido tiene en Marion otro nombre: «donación» ${ }^{32}$. En efecto, el filósofo francés, que dialoga fundamentalmente con Husserl y con Heidegger, en referencia a este último, insiste en que existe una realidad previa al ser, y dicha realidad previa, no tenida suficientemente en cuenta, se llama donación. Hay una equivalencia entre «ser mismo» y «ser dado» que nos ha de llevar a pensar el ser según la lógica del ofrecimiento y del regalo ${ }^{33}$.

De esta manera, Marion intenta exponer un nuevo acercamiento a la problemática de aquello que se encuentra dado, subrayando así que no es la donación la que pertenece a la fenomenología, sino que es la fenomenología la que pertenece enteramente a la donación. O de otra manera, la única forma de mostración o aparición es la donación. De hecho, y en gran medida para este filósofo, la historia de la fenomenología es aquella en la que se van añadiendo distintos modos de donación auténtica a los sucesivos estudios: la carne, la diferenciación entre ser y ente, la auto-afección, la diferencia... Afirma el filósofo francés:

La donación pertenece menos a la fenomenología de lo que la fenomenología depende por entero de la donación. En efecto, la donación no ofrece solamente a la fenomenología un concepto entre otros, ni tampoco el acto privilegiado para acceder a ella misma, sino que le abre precisamente el campo de la fenomenicidad. Y ello porque nada aparece si

${ }^{32}$ Para la reflexión que sigue, cfr. Horner, R., Rethinking God as Gift. Marion, Derrida, and the Limits of Phenomenology, New York: Fordham University Press, 2001, 115-152.

33 Cfr. Marion, J.-L., Siendo dado. Ensayo para una fenomenología de la donación, Madrid: Síntesis, 2008, 73 . 


\section{JOSÉ SERAFÍN BÉJAR}

no es dándose a la mirada pura; el concepto fenómeno equivale pues exactamente al de una donación de sí en persona; la puesta en escena del fenómeno se produce como la entrega de un don. Cuando se trata de fenomenicidad, todo se decide, en última instancia, por donación y a partir de la donación absoluta, «término último» ${ }^{34}$.

En este sentido, y como un avance consciente de la filosofía de Heidegger, Marion subraya que «lo que se muestra, primero se da» ${ }^{35}$. Es cierto que Heidegger entiende el ser desde la conocida expresión alemana Es gibt, «se da», pero a juicio de Marion, el filósofo alemán termina por no abrir las potencialidades que este camino posee. Intentemos comprender el porqué.

Tal como ya dijimos, Heidegger afirma que, mientras que el ente es, el ser se da. El acceso al ser sólo se posibilita por su fenomenicidad en el ente, es decir, que para que el ser pueda mostrarse, necesita de una donación. Éste podría significarse como el cambio más decisivo entre Ser y tiempo y su obra posterior Tiempo y ser: la pertinencia de pensar el ser en el horizonte de la donación. Si el ente es el que es, el ser no se puede pensar en el horizonte del ser, sino en el horizonte más decisivo de la donación. Esto explicaría además una característica fundamental del mismo: su retracción. La diferencia fundamental entre ser y ente estaría basada en el concepto de retraimiento, ya que sólo es posible hablar del don en la retracción del mismo. Podemos leer en la obra Siendo dado:

El ser se retira del ente, porque lo da; ahora bien, toda donación implica que el dar desaparezca (se retire) en la exacta medida en la que el don aparece (se avanza), precisamente porque dar implica «abandonarirse». El ser se avanza así en su propio retraimiento -esta paradoja sólo puede esclarecerse mediante la donación-. Únicamente la donación descubre el ente en $(y \sin )$ su ser, así pues, tanto la diferencia ontológica como el nihilismo ${ }^{36}$.

Ahora bien, cuando Heidegger habla de que el ser «se da», ¿de quién está hablando? ¿quién es el que se da? Para Marion se encuentra aquí el punto débil de esta propuesta. Heidegger acaba descuidando el primado de la donación cuando bautiza este «se» como Ereignis, ya que el acontecimiento propiciante

${ }^{34}$ Ibid., 70.

${ }^{35}$ Ibid., 35.

${ }^{36}$ Ibid., 83. 
termina por sustituir a la donación. Merece la pena atender a la explicación del filósofo francés:

En definitiva, hay que escribir el «se» del «se da» «en mayúsculas», para que ningún nombre propio venga a relegar la donación que pone en práctica al rango de una causación o de una efectuación por medio de uno u otro ente, privilegiado o no. La indeterminación no salva solamente el enigma, sino que defiende la pura donación [...] para que el «se da» resulte verdadero, el «se» tiene que pensarse en y a partir del «dar», indeterminado pues y anónimo en cuanto tal; si no es así, recaería inevitablemente en el ente (incluso en el ente supremo). Sólo el enigma del «se» anónimo salvaguarda la donación.

Ahora bien, en contra de la prudencia declarada, Heidegger suprime inmediatamente el anonimato del «se» y se ofusca así el enigma. Viola la prohibición tan pronto como él mismo la ha formulado, bautizando el «se» con el nombre de «Ereignis»: «[...] el "se" que da en el "se da ser", "se da tiempo" se atesta como un advenimiento (Ereignis)» ${ }^{37}$.

A partir de este análisis, en el que la acusación de haber descuidado la donación también alcanza a la filosofía de Husserl, Marion reclama la necesidad de ir más allá de las dos reducciones operadas en fenomenología: la reducción trascendental y la ontológica. De este modo, se nos habla de una tercera reducción, que tendría como caracterización la de ser una última y definitiva reducción. Para Marion, reducir consiste en dejar «manifestarse lo que tiene derecho a manifestarse, usando sólo su fuerza de suspensión contra las violencias teóricas ilegítimas» ${ }^{38}$. El método que posibilita esta tercera reducción tiene las características de un contra-método, cuyo objetivo final sería favorecer las condiciones en las que se permite que la manifestación se diga desde sí y por sí misma, sin aplicarle camisa de fuerza alguna que constriña la legitimidad de su autoexpresión. Es aquí donde nos vamos a encontrar con lo que Marion llama «el principio de los principios»; a saber: «a tanta reducción, tanta donación» ${ }^{39}$. Llegamos así al intento de reducción pura que no mide la donación desde otro rasero que no sea el de la donación misma, mostrando cómo, a mayor radicalidad de la reducción, se nos ofrece una mayor amplitud y alcance de la donación misma.

\footnotetext{
37 Ibid., 83 ss.

38 Ibid., 42 ss.

39 Ibid., 49.
} 


\section{JOSÉ SERAFÍN BÉJAR}

Marion ilustra su propuesta con un conocido ejemplo: el del cuadro. No habla de un cuadro que tenga que ser especialmente significativo dentro de la historia del arte. Se trata, más bien, de un cuadro mediano, sin especiales dotes de excelsitud artística. La reducción a su pura fenomenicidad pone de manifiesto, en primer lugar, que el cuadro no hace su aparición en cuanto que subsiste. Para ello, el filósofo francés refiere cómo sería posible cambiar completamente el soporte del cuadro, sometiéndolo a un proceso intenso de restauración, que llegaría incluso a trasportar los pigmentos de distintos colores a otro soporte, sin que se viera alterado en absoluto lo que acontece en la aparición de dicho cuadro. En segundo lugar, tampoco el cuadro aparece en referencia a su utilidad. Es más, sólo cuando la utilidad de algo se quiebra, pensemos en un ordenador que deja de funcionar, la cosa misma hace su aparición en su verdad desnuda; o de otra manera, la cosa aparece porque ha dejado de funcionar. En tercer lugar, tampoco el cuadro se muestra en cuanto que ente, ya que no se ve lo que es, sino aquello que acaece más allá de lo óntico. En una exposición, a propósito de esto que decimos, no se pretende mostrar un ente, sino una aparición. De ahí que una exposición se comprenda desde una continua revisitación, ya que no se va a la exposición a ver una cosa, sino a dejarse afectar por un acontecimiento que, en cada nueva ocasión, tiene la virtualidad de aparecer. Si fuera un ente lo que se expone, bastaría con haberlo visto una vez.

Así pues, en el fenómeno reducido del cuadro lo que aparece no es ni su subsistencia, ni su utilidad, ni su enticidad, sino la donación como puro advenimiento. Ante un cuadro, nos dirá Marion, no hay nada que ver, ya que la esencia del cuadro es su invisibilidad. En efecto, el cuadro no es, el cuadro aparece, y únicamente puede aparecer porque se da. De ahí otro principio de la fenomenología de Marion, ya antes apuntado, que reza «nada aparece si no se da» ${ }^{40}$.

Es interesante anotar cómo, a partir de lo dicho en referencia al cuadro, se ofrece una extrapolación a toda la fenomenicidad en cuanto tal. Donde falta una evidente cosificación o entificación es más fácil encontrar, a juicio de Marion, fenómenos reducidos que evidencian esta necesaria clave de la donación. De hecho, el filósofo nos habla de dar tiempo, dar vida, dar sentido, dar la palabra... En estas acciones mencionadas no se da ningún objeto o ente, sino

${ }^{40}$ Ibid., 107. 
una realidad que apunta a la pura donación. Si queremos que el fenómeno aparezca absolutamente, tiene que ser reducido únicamente a lo dado: ni subsistencia, ni utilidad, ni ente. Ésta podría ser una digna conclusión de todo lo dicho. Vayamos a sus propias palabras:

El fenómeno se reduce pues tanto más a lo dado en la medida en que asume la puesta entre paréntesis de su enticidad y de su realidad mundanas. Por consiguiente, no nos sorprenderá que los fenómenos más evidentemente reductibles a su donación se encuentren de entrada en los campos semánticos en los que, por definición, falta la realidad cósica y la enticidad posicionada [...] por definición, no dan nada, ningún objeto, ningún ente; y por esta razón misma, dan tanto más evidentemente, tanto más netamente y a fondo en la medida en que nada resiste a la reducción ni ofusca el efecto puro de donación, al que se reconducen sin resto $\operatorname{alguno}^{41}$.

Esta mención del pensamiento de Marion podría ayudar a un discernimiento de las racionalidades hegemónicas en el espacio universitario; algo a lo que estamos aludiendo reiteradamente en el trascurso de nuestra reflexión. Uno de los fenómenos más importantes a considerar en la evolución del espacio universitario de los últimos años es la subordinación del mismo a los intereses del mercado. La vida de los seres humanos se empobrece cuando se confunde el valor con el precio, y la propuesta de pensamientos como el de Marion, que ponen el acento en lo dado, de modo gratuito e incondicionado, pueden ayudarnos a pensar la realidad de un modo más hondo e incluso transgresor.

$\mathrm{Al}$ mismo tiempo, esta breve presentación de la filosofía de Marion evidencia las connivencias que este pensamiento tiene con el cristianismo. No en vano, la teología de H. U. von Balthasar, de orientación claramente fenomenológica, siempre ha sido un pensamiento inspirador para este filósofo francés $^{42}$. Al mismo tiempo, encontramos en la reflexión de Marion la categoría de «exceso», que es también uno de los vectores principales de la obra del teólogo belga A. Gesché ${ }^{43}$. Conviene recordar, de nuevo aquí, que el cristianismo primitivo realizó un discernimiento de las racionalidades, vigentes en su tiempo, desde la categoría de Sarx, que hemos referenciado a la filosofía de Levi-

\footnotetext{
41 Ibid., 104.

42 Cfr. Von Balthasar, H. U., El cristianismo es un don, Madrid: Paulinas, 1973.

43 Cfr. Gesché, A., Dios para pensar: El sentido, Salamanca: Sígueme, 2004.
} 
nás, y desde la categoría de Ágape, que bien podría ser referenciada a la filosofía de Marion. En efecto, el ágape es la forma del amor cuando se presenta desde una gratuidad incondicional; es decir, un amor de pura donación ${ }^{44}$.

\section{ConClusión}

El enclave universitario es connatural a la naturaleza de la teología, y una correcta inserción de la misma en el seno de esta institución puede tornarse en el comienzo de una colaboración enriquecedora para ambas. Pensamos que esta relación recíproca ha quedado suficientemente mostrada en la reflexión que ahora finaliza.

No obstante, nos gustaría acabar explicitando los beneficios que puede tener para la teología su pertenencia, como una rama más del saber, al ámbito de la universidad del siglo XXI. O de otra manera, ¿qué aporta la universidad a la teología? La hipótesis de fondo que ha guiado nuestra reflexión ha sido que dicha pertenencia podría ofrecer a la teología una redefinición de su quehacer a la manera de un discernimiento permanente de las racionalidades coexistentes en el espacio universitario. A continuación, vamos a concretar esta hipótesis en tres aportaciones más específicas que, aunque han aparecido a lo largo de nuestra exposición, recogemos ahora en forma de tesis. De esta manera, pretendemos visibilizar algunos de los elementos que están en juego en toda teología que quiera estar a la altura de su vocación universitaria.

Primera tesis: la universidad reta a la teología a realizar el esfuerzo por universalizar la narrativa evangélica, estimulándola a dar el paso del «relato» al «concepto» o al «sistema».

${ }^{44}$ «Pero agape no es ni el amor carnal ni el pasional, que los griegos denominan eros, ni el amor tierno, apacible, y que ellos llaman filia, de las parejas unidas o de los padres por sus hijos pequeños. Agape va más allá. Es el amor que da en lugar de recibir, el amor que se empequeñece en vez de ocupar todo el espacio, el amor que desea el bien del otro antes que el suyo propio, el amor liberado del ego. Uno de los pasajes más alucinantes de la alucinante correspondencia de Pablo es una especie de himno al agape que es tradicional leer en las misas de matrimonio [...] Renan lo considera -y coincido con él- el único pasaje del Nuevo Testamento que está a la altura de las palabras de Jesús, Brahms le puso música en la última de sus sublimes Cuatro canciones serias», en CARRÈRE, E., El Reino, Barcelona: Anagrama, 2015, 169 ss. Es interesante atender a la apreciación que Carrère, escritor agnóstico notoriamente relevante en Francia, ofrece sobre la especificidad del amor cristiano, en esta novela que ha sido galardonada con distintos premios. Aunque no se esté de acuerdo con todas las afirmaciones que el escritor hace en la misma, se agradece el esfuerzo de comprensión del cristianismo como algo «dado», que ofrece su propia lógica de auto-comprensión. 
Ésta es la tarea más nuclear a la que la teología ha tenido que dar respuesta a lo largo de su historia. En efecto, la narrativa de la vida de un judío del siglo I tiene la vocación de convertirse en dadora de sentido y de significación existencial para todo ser humano de cualquier tiempo y lugar. Ya el cristianismo de la primera hora fue consciente de este desafío. San Pablo, en el Areópago, intentó una primera propuesta de teología cristiana cuando trató de unir el culto al dios desconocido con la presencia histórica de Jesús de Nazaret (cfr. Hch 17,23). A propósito de este discurso, nos dice González de Cardedal:

La universalidad de la razón, que aparecía en la primera parte del discurso de Pablo, chocaba con la particularidad de la historia que proponía la segunda [...] ¿Tiene el evangelio una universalidad, que le permite establecer conexión y anclar en la tierra firme de la razón universal, o por el contrario es un fenómeno absolutamente particular, interesante quizá e instructivo pero sin capacidad para reunir a los fragmentos dispersos y ser tronco del que otras innumerables ramas tomen savia nueva y florezcan nuevos frutos? ${ }^{45}$

Segunda tesis: la universidad ofrece a la teología, como recurso permanente, un diálogo con las racionalidades vigentes, salvándola de la tentación de convertirse en superstición o mera creencia.

Esto es algo que aparece de modo profuso en la obra de J. Ratzinger (Benedicto XVI) y que estuvo muy presente en los diálogos que mantuvo en su tiempo con el reconocido filósofo J. Habermas. Para ello, Ratzinger acudía a la reflexión de los Padres de la Iglesia que encontraron, desde los inicios mismos de la inclusión del cristianismo en contexto helénico, un partner natural en el Logos de los filósofos, salvando a la teología de degenerar en mito encubridor o legitimador del poder político. Son muy conocidas las palabras del entonces cardenal de la Congregación para la doctrina de la fe:

Hemos visto que en la religión hay patologías altamente peligrosas que hacen necesario considerar a la luz divina de la razón como una especie de órgano de control por el que la religión debe dejarse purificar y regular una y otra vez, cosa que ya pensaban los Padres de la Iglesia [...]

45 GonZÁlez de Cardedal, O., El lugar de la teología, Madrid: Real Academia de Ciencias Morales y Políticas, 1986, 61. También cfr. IDEM, El quehacer de la teología, Salamanca: Sígueme, 2008, 439-453. 
Por ello, yo hablaría de una correlación necesaria de razón y fe, de razón y religión, que están llamadas a purificarse y regenerarse recíprocamente, que se necesitan mutuamente y deben reconocerlo ${ }^{46}$.

Tercera tesis: la universidad aporta a la teología la agudización de su dimensión crítica, haciendo posible la denuncia de todo aquello que deshumaniza a la persona.

Como hemos apuntado anteriormente, la presencia de diversas matrices ideológicas en el espacio universitario tiende a recrear nuevas divinizaciones que ponen al ser humano a su servicio. Esto es algo que señalaba con mucha clarividencia el filósofo francés $M$. Gauchet, cuando afirmaba la tendencia a que «la alteridad arrebatada a la trascendencia normativa resurge invisible, innombrable para los actores pero indudablemente eficaz, en el interior del mecanismo político» ${ }^{47}$ (nosotros diríamos, en el interior del mecanismo universitario). Pues bien, la teología actualiza aquí, como contención crítica a estas trasmutaciones de lo religioso, un concepto que se ha hecho común en la reflexión teológica contemporánea, procedente de la teología política de J. B. Metz: la reserva escatológica. En efecto, la dimensión crítica de la teología en medio de la universidad brota de su tensión escatológica:

La esperanza crítico-creadora de los cristianos no es sencillamente expresión de un «optimismo militante» (E. Bloch). No canoniza el progreso instituido por nosotros. Sino que está fundada y seguirá estándolo siempre en una esperanza... contra toda esperanza, contra toda esa esperanza que nosotros asociamos con los dioses erigidos por nosotros mismos, de nuestra sociedad secularizada ${ }^{48}$.

Toca ya concluir. Y lo hacemos con la pregunta fundamental que abría nuestra reflexión: ¿por qué «este» hombre es «el» hombre donde «todo» hombre encuentra salvación? El cristianismo, para ser fiel al encargo recibido, tiene que seguir ofreciendo su aporte de sentido como propuesta universalizable de existencia. Confiamos en que la colaboración mutua entre universidad y teología pueda seguir prestando un servicio a la vida plena de los seres humanos de nuestro mundo.

\footnotetext{
${ }^{46}$ RatZinger, J., «Lo que cohesiona el mundo. Las bases morales y pre-políticas del Estado», en Ratzinger, J. y Habermas, J., Dialéctica de la secularización. Sobre la razón y la religión, Madrid: Encuentro, 2006, 66-67 ss.

47 Gauchet, M., La religión en la democracia, Madrid: El Cobre, 2003, 24.

48 Metz, J. B., Teología del mundo, Salamanca: Sígueme, 1971, 124 ss.
} 


\section{Bibliografía}

Adorno, Th. W., «Minima moralia. Reflexiones desde la vida dañada», en Tiedemann, R. (ed.), Obra completa, IV, Madrid: Akal, 2004.

Adorno, Th. W., Popper, K. R., Dahrendorf, R., Habermas, J., Albert, H. y PiLOT, H., La disputa del positivismo en la sociología alemana, BarcelonaMéxico D.F.: Grijalbo, 1973.

BÉJAR, J. S., «Cristianismo, Islam e Ilustración. A propósito del discurso de Benedicto XVI en la Universidad de Ratisbona», Pensamiento 64 (2008) 1025-1042.

BÉJAR, J. S., El discernimiento de las racionalidades en F. F. Hinkelammert, Granada: UGR, 2016.

BÉJAR, J. S., «La evangelización de la universidad como discernimiento de las racionalidades», Cristianismo, universidad y cultura 6 (2013) 57-71.

BÉJAR, J. S., «Para una teología de la misericordia», Proyección 63 (2016) 145158.

Cantos Aparicio, M., Razón abierta. La idea de universidad en f. Ratzinger/Benedicto XVI, Madrid: BAC, 2015.

CARrère, E., El Reino, Barcelona: Anagrama, 2015.

Gauchet, M., La religión en la democracia, Madrid: El Cobre, 2003.

GeschÉ, A., Dios para pensar: El sentido, Salamanca: Sígueme, 2004.

González de Cardedal, O., La teología en España (1959-2009). Memoria y prospectiva, Madrid: Encuentro, 2010.

González de Cardedal, O., Fundamentos de cristología, I, Madrid: BAC, 2005.

González de Cardedal, O., El lugar de la teología, Madrid: Real Academia de Ciencias Morales y Políticas, 1986.

GonzÁlez de CARDEDAL, O., El quehacer de la teología, Salamanca: Sígueme, 2008.

Habermas, J., Conocimiento e interés, Madrid: Taurus, 1988.

Hegel, G. W. F., Fenomenología del Espíritu, Madrid: FCE, 2000.

Heidegger, M., Carta sobre el humanismo, Madrid: Alianza, 2001.

HeIDEgGer, M., Identidad y diferencia (edición bilingüe), Barcelona: Anthropos, 1988.

HenRY, M., Encarnación, Salamanca: Sígueme, 2001. 
Horner, R., Rethinking God as Gift. Marion, Derrida, and the Limits of Phenomenology, New York: Fordham University Press, 2001.

Kasper, W., fesús el Cristo, Salamanca: Sígueme, 19949.

LESSING, G. E., «Sobre la demostración en espíritu y fuerza», en ANDREU Rodrigo, A. (ed.), Escritos filosóficos y teológicos, Madrid: Editora Nacional, 1982.

LEVINAS, E., Totalidad e infinito. Ensayo sobre la exterioridad, Salamanca: Sígueme, 2002.

LeVINAS, E., De otro modo que ser o más allá de la esencia, Salamanca: Sígueme, 2003.

Marion, J.-L., Siendo dado. Ensayo para una fenomenología de la donación, Madrid: Síntesis, 2008.

Martín Morillas, A. M., La nada en el segundo Heidegger y el vacío de oriente. Hermenéutica contrastativa, Granada: Editorial de la Universidad de Granada, 2003.

Merleau-Ponty, M., Fenomenología de la percepción, Barcelona: PlanetaAgostini, 1985.

Metz, J. B., Teología del mundo, Salamanca: Sígueme, 1971.

Ratzinger, J., Iglesia, ecumenismo y política. Nuevos ensayos de eclesiología, Madrid: BAC, 1987.

RATZINGER, J., Introducción al cristianismo. Lecciones sobre el credo apostólico, Salamanca: Sígueme, 2005.

RATZINGER, J., «Lo que cohesiona el mundo. Las bases morales y pre-políticas del Estado», en Ratzinger, J. y Habermas, J., Dialéctica de la secularización. Sobre la razón y la religión, Madrid: Encuentro, 2006.

Ricoeur, P., Finitud y culpabilidad, Madrid: Trotta, 2011.

Rodríguez Duplá, L., Prólogo, en Ratzinger, J. y Habermas, J., Dialéctica de la secularización. Sobre la razón y la religión, Madrid: Encuentro, 2006.

SUdAR, P., «¿La filosofía amor a la sabiduría o sabiduría del amor? Diálogo con Emmanuel Levinas», Teología 33 (1979) 63-70.

Tracy, D., «Theology: Comparative Theology», en Jones, L. (ed.), Encyclopedia of Religion, Detroit: Macmillan Reference, 2005.

Tracy, D., The Analogical Imagination: Christian Theology and the Culture of Pluralism, New York: Crossroad, 1991.

Von Balthasar, H. U., El cristianismo es un don, Madrid: Paulinas, 1973. 